\title{
A expansão do rastreio do câncer do colo do útero e a formação de citotécnicos no Brasil
}

I ${ }^{1}$ Luiz Antonio Teixeira, ${ }^{2}$ Marco Antonio Teixeira Porto,

${ }^{3}$ Letícia Pumar Alves de Souza I

Resumo: O trabalho discute a emergência da categoria profissional dos citotécnicos no Brasil e sua trajetória entre a década de 1970 e o final dos anos 1990. No início desse período, a Organização Pan-americana de Saúde passou a considerar o câncer do colo do útero como um grave problema de saúde pública, passível de ser controlado nos países em desenvolvimento. Nesse contexto, surgem as primeiras campanhas de rastreamento da doença no país. A institucionalização dessas campanhas transformou os citotécnicos em elementos indispensáveis para a viabilização do controle da doença. Com a expansão da demanda por sua atividade e o surgimento das primeiras iniciativas para sua formação, novas questôes começam a surgir. Como formar, em quantidade e qualidade adequadas, esses novos profissionais? Qual a grade curricular adequada às suas tarefas e responsabilidades? Como monitorar o funcionamento dos cursos? No campo da normatização da nova atividade, outras questôes se apresentam: como garantir o monopólio sobre a atividade exercida, como caracterizar sua especificidade, qual a formação exigida aos que vão exercêla? Tais pontos passam a ser temas de embates e negociações, num típico processo de consolidação de uma nova profissão. O processo de institucionalização do programa de prevenção do câncer do colo do útero e a consequente necessidade de garantia de qualidade dos exames executados fizeram com que essas questões voltassem ao centro das atenções. Este estudo visa a contribuir para a ampliação do conhecimento sobre a formação do citotécnico, e em âmbito mais geral, ao processo de formação profissional em saúde no Brasil.

1 Pesquisador, Departamento de Pesquisa da Casa de Oswaldo Cruz / Fiocruz. Endereço eletrônico: teixeira@fiocruz.br

2 Professor associado, Universidade Federal Fluminense. Endereço eletrônico: m.porto@globo.com

${ }^{3}$ Doutoranda, Casa de Oswaldo Cruz / Fiocruz. Endereço eletrônico: leticiapumar@ gmail.com

Recebido em: 07/05/2011 Aprovado em: 31/10/2011. 


\section{Introdução}

O citotécnico ou técnico em citologia é um profissional que cumpre importante função de apoio ao diagnóstico citológico. No âmbito do teste de Papanicolaou, ele tem como principal função examinar as lâminas elaboradas a partir do material colhido e encaminhar os casos considerados atípicos para avaliação do médico citopatologista. Dessa forma, é o responsável pela triagem do material citopatológico, permitindo que o médico examine somente os casos suspeitos, em geral 10 a 30\% do total. Especialmente com relação ao câncer do colo do útero, os profissionais da área da saúde envolvidos na melhoria das condições do seu rastreio no país demandam, há várias décadas, a necessidade de capacitação de recursos humanos para essa função. Em geral, defendem que a atuação de profissionais com formação específica e de qualidade poderia reduzir custos e melhorar a qualidade dos programas de prevenção.

O surgimento dos primeiros cursos de formação de citotécnicos no país foi uma consequência das iniciativas pioneiras de rastreamento de câncer de colo de útero baseadas na utilização do exame de Papanicolaou. A institucionalização das campanhas de rastreio do câncer do colo do útero fez do citotécnico um elemento indispensável para a realização e ampliação de programas de controle da doença. Sua função, até então relegada a médicos residentes, sob a supervisão de patologistas, ou mesmo aos próprios patologistas, passou a ser central para a saúde pública, à medida que a ampliação do número de exames requeria maior número de técnicos para leitura inicial das lâminas. Com a expansão da demanda pela atividade do citotécnico e o surgimento das primeiras iniciativas para sua formação, novas questões começavam a surgir. O monopólio sobre a atividade exercida, a caracterização dessa atividade e a formação específica dos que vão exercê-la passaram a ser temas de embates e negociações.

Este trabalho tem por objetivo relacionar o surgimento dos cursos de formação de citotécnicos ao movimento de expansão de programas e campanhas de rastreamento do câncer de colo do útero na Brasil. Adotando uma perspectiva histórica, acompanha a trajetória da formação e da tentativa de regulamentação deste profissional. A partir das questôes levantadas pela sociologia das profissões, analisa as dificuldades de regulamentação e de padronização dos cursos de formação dos citotécnicos no país. 


\section{O controle do câncer do colo do útero no Brasil}

Em todo o mundo, o câncer de colo do útero é o segundo tipo de câncer mais incidente entre as mulheres, sendo responsável pelo óbito de cerca de $275 \mathrm{mil}$ mulheres por ano. As mulheres com idade entre 25 e 64 anos, que já tiveram atividade sexual, estão mais sujeitas à ocorrência de lesões que podem evoluir para o câncer quando não tratadas. É possível reduzir a ocorrência de novos casos com o diagnóstico e tratamento adequado das lesões iniciais.

No Brasil (INCA, 2011), a estimativa atual deste tipo de câncer é de 17.540 casos novos por ano, com um risco estimado de 17,5 casos a cada $100 \mathrm{mil}$ mulheres. Sem considerar os tumores de pele não-melanoma, este é o tipo de câncer mais incidente na Região Norte (24/100.000). Nas regiōes Centro-Oeste (28/100.000) e Nordeste (18/100.000), ocupa a terceira posição e nas regiōes Sudeste (16/100.000) e Sul (14/100.000), a quarta.

Os primeiros programas de rastreamento populacional do câncer do colo do útero surgiram em algumas regiōes dos Estados Unidos, na década de 1950 (HAKAMAL et al., 1985). Na Europa, a Noruega criou um programa desse tipo ainda em 1959; no ano seguinte, a Dinamarca também implantou um programa de rastreio. Nos anos 1960, vários países nórdicos criaram programas similares e, em 1966, o rastreamento do câncer do colo do útero já fazia parte do Serviço Nacional de Saúde da Inglaterra (LOWY, 2010). Nesse período, a Organização Panamericana de Saúde (OPAS) passou a ver o câncer do colo do útero como um importante problema de saúde pública nos países da América Latina. A partir da constatação dos altos índices da doença na região, e de que na maioria desses países as ações de prevenção eram muito restritas, a OPAS passou a propor a elaboração de programas específicos para o controle da doença a partir da utilização maciça do teste de Papanicolaou (HORWITZ, 1972).

Logo, alguns médicos brasileiros começaram a advogar a utilização de campanhas e programas para o rastreamento do câncer do colo do útero como a forma mais adequada de controle da doença para o país. Em meados dos anos 1960, começam a surgir, ainda de forma desconexa, algumas campanhas de rastreamento desse câncer. Porto Alegre, Bahia, e principalmente São Paulo foram precursores dessas iniciativas. A prevenção do câncer do colo do útero começava a deixar o âmbito dos consultórios particulares, hospitais especializados 
e gabinetes ginecológicos e se transformava numa atividade atinente à saúde pública. Seguindo a linhas das campanhas de rastreamento populacional norteamericanas e europeias, essas iniciativas tinham como base a utilização da citologia exfoliativa como análise inicial, prevendo o uso da colposcopia e se necessário da biópsia em casos onde a análise das lâminas mostrasse alguma anormalidade (TEIXEIRA; LOWY, 2011).

O Programa de Controle de Câncer Cervical de Campinas (SP) foi a primeira experiência desse tipo com uma grande envergadura e continuidade temporal posta em prática no país. Seu surgimento remonta a 1965, quando foi criado o Departamento de Ginecologia e Obstetrícia da Universidade Estadual de Campinas, então liderado pelo médico José Aristodemo Pinotti, que havia se especializado na Europa. O programa conseguiu uma escala de atendimento sem precedentes no país, e em dez anos seu número de exames citológicos anuais se elevou de 461 a 19.195, sendo que as atipias encontradas passaram a declinar a partir do seu quarto ano de existência (PINOTTI; ZEFERINO,1987).

Seguindo as diretrizes da OPAS, o programa de Campinas utilizava pessoal paramédico para a coleta descentralizada de material - que era efetuada em postos municipais e estaduais de saúde - e treinava técnicos para a análise das lâminas, atividade centralizada que era realizada em um laboratório específico construído com essa finalidade. Trabalhando em colaboração com postos de saúde municipais e estaduais, hospitais e outras instituições médicas filantrópicas, o programa conseguiu estabelecer uma nova metodologia para a prevenção do câncer do colo do útero no país.

No final da década de 1960, algumas instituições paulistas começaram a elaborar campanhas para o controle do câncer do colo do útero que seguiam a metodologia do programa de Campinas. A primeira delas foi o Hospital filantrópico São Camillo, que criou um instituto de prevenção e tratamento de câncer ginecológico em 1967, com fundos próprios e do Estado, que passou a ser liderado pelo ginecologista Sampaio Góes. Em 1968, Sampaio Góes inaugurava uma nova instituição direcionada à prevenção do câncer de colo do útero. O Instituto Brasileiro de Estudos e Pesquisas em Obstetrícia e Ginecologia (IBEPOG), também criado em associação com o governo estadual, patrocinou diversas campanhas contra o câncer do colo do útero no Estado. 
Em 1972, Sampaio Góes foi alçado ao cargo de diretor da Divisão Nacional

de Câncer (DNC), do Ministério de Saúde. Sua passagem pelo cargo teria como marca o desenvolvimento de ações inovadoras. Na sua gestão, foi criado o Plano Nacional de Controle de Câncer (PNCC) que, entre seus diversos objetivos, enfatizava a ampliação das açôes de prevenção ao câncer de colo do útero pelo incentivo à utilização da citologia exfoliativa. Em 1975, Góes deixou o DNC e retornou a São Paulo, onde implantou um programa estadual de prevenção ao câncer do colo do útero baseado em suas experiências anteriores na cidade e no trabalho efetuado por Pinotti em Campinas. Caracterizado como um programa permanente, liderado pela Fundação Centro de Pesquisa em Oncologia (FCPO) - criada em 1974 e por ele dirigida -, o programa integrava os postos de saúde do estado e dos municípios, alguns consultórios privados e até algumas unidades móveis (ônibus e vagões de trens) que serviam como base para a coleta de exames. A leitura das lâminas era efetuada no FCPO e os tratamentos e cirurgias realizados no Instituto Brasileiro de Controle do Câncer, hospital privado criado por Góes, que funcionava com financiamento do governo do estado (CAPUCCI, 2003).

Nesse mesmo período, em âmbito nacional, novas iniciativas em relação ao câncer do colo do útero começavam a ser postas em prática. A partir do final dos anos 1970, em meio à crise que prenunciou o fim da ditadura, as reivindicações de diversos setores sociais pela ampliação do acesso aos serviços de saúde possibilitaram a criação de novos programas federais de prevenção ao câncer do colo do útero. O Programa de Atenção Integral à Saúde da Mulher (PAISM), criado em 1982, tinha como um de seus objetivos a ampliação das ações educativas e o apoio a projetos estaduais de prevenção. O Pro-Onco surgiu três anos depois e visava a apoiar ações para o controle de diversos tipos de câncer. O programa funcionava numa parceria do Governo Federal com as secretarias estaduais e municipais de Saúde, as universidades e hospitais de câncer, visando, entre outras metas, a dar apoio a campanhas educativas que pudessem redundar na ampliação da detecção do câncer do colo do útero e a implantação de um sistema de informação para monitorar as ações do programa (ABREU, 1997).

Apesar dessas iniciativas, em meados da década de 1980, o controle do câncer de colo do útero no país ainda era bastante incipiente, apresentando resultados pouco promissores. Pesquisa realizada pelo Instituto Nacional de Câncer, durante 
o ano de 1984, mostrou que naquele momento, apenas 7\% das unidades básicas das secretarias de Saúde efetuavam testes citológicos. No âmbito da medicina previdenciária, não havia informações sobre a realização desses exames, sendo que um cálculo a partir das consultas ginecológicas realizadas permitia avaliar que menos de $16 \%$ das mulheres brasileiras, acima dos 15 anos, haviam se submetido ao exame (AQUINO et al., 1986).

Somente a partir do final dos anos 1980, com o processo de reforma sanitária que redundou na fusão da assistência médica previdenciária com a saúde pública por meio da criação do Sistema Único de Saúde (SUS), o perfil do controle do câncer de colo do útero no país começaria a mudar. A partir de 1995, como consequência das demandas do movimento feminista, reforçadas pela participação do Brasil na, VI Conferência Internacional da Mulher, se organizou uma grande campanha de rastreamento de câncer do colo do útero. O projeto, então denominado Viva Mulher, foi implantado pelo INCA e visava a desenvolver as bases para a estruturação de um programa de rastreamento do câncer do colo do útero de alcance nacional.

O objetivo do projeto piloto Viva Mulher era reduzir a incidência e a mortalidade pela doença, através da ampliação do acesso das mulheres brasileiras ao exame citopatológico, priorizando as mulheres sob maior risco e garantindo o acolhimento e o tratamento adequado da doença e das lesóes precursoras em $100 \%$ dos casos. O projeto piloto foi implantado em seis localidades: Belém (PA); Curitiba (PR); Brasília, Tabatinga, Ceilândia e Samambaia (DF); Recife (PE), Campo Grande, Bangu e Santa Cruz (bairros da zona oeste do Rio de Janeiro-RJ) e no Estado de Sergipe (em janeiro de 1998).

Em setembro de 1998, antes mesmo da conclusão do projeto piloto iniciado pelo INCA, o Ministério da Saúde chamou a si a responsabilidade pelo projeto e lançou uma campanha nacional que se convencionou chamar "fase de intensificação". A opção por uma campanha nacional causou divergências entre os profissionais da área, pois muitos sublinhavam a pouca eficácia de açóes nacionais temporárias e a necessidade de criação de um programa permanente e padronizado para o controle do câncer de colo do útero. Apesar das controvérsias, a campanha nacional foi executada pelo Ministério da Saúde e foram examinadas 3.177.740 mulheres, em todo o país. ${ }^{1}$ Essa campanha tinha como metas a realização de coleta de material para o exame citológico em $70 \%$ 
das mulheres, com idade entre 35 e 49, e que nunca tivessem realizado o exame; garantir que todos os resultados desses exames fossem entregues às mulheres em mais ou menos um mês; tratar todas as mulheres com diagnóstico de cérvicocolpite e acompanhar todas as mulheres com citologia positiva até que efetuassem o tratamento e obtivessem a alta (BRASIL, 2002). Apesar da magnitude de seus objetivos e resultados globais, vários problemas operacionais dificultaram o bom andamento da campanha. As maiores dificuldades se concentraram na leitura das lâminas e no segmento das mulheres que apresentaram exames alterados. Nesses aspectos, os resultados da campanha foram muito abaixo do esperado (BRASIL, 2000). Segundo as fontes oficiais, apesar dos problemas, foram realizados exames citopatológicos em todas as mulheres brasileiras, da faixa etária de 35 a 49 anos de idade, a partir de uma mobilização de 97,9\% dos municípios brasileiros (BRASIL, 2002).

A partir do mês de abril de 1999, foi iniciada a "fase de consolidação" das ações, com a expansão do Programa Viva Mulher - Programa Nacional de Controle do Câncer do Colo do Útero. Essa nova experiência demonstrou que, para a progressiva consolidação dessas ações, seriam necessários ajustes nas rotinas de seguimento da mulher com diagnóstico positivo; ampliação da capacitação de recursos humanos, por meio de treinamento em todos os níveis; aumento do número de laboratórios de citopatologia com conhecimento e utilização do Siscolo e, no âmbito mais geral, a introdução da taxa de cobertura da população feminina pelo exame citopatológico como indicador de atenção básica dos municípios brasileiros (BRASIL, 2002).

A partir de uma avaliação de resultados, realizada em 1999, os técnicos do INCA concluíram que a política de controle do câncer do colo do útero deveria se pautar na oferta de exames citológicos de rotina, acompanhados de grandes campanhas trienais. Com um ano de atraso, uma nova campanha foi efetuada em 2002, tendo como alvo prioritário as mulheres com idade entre 35 e 49 anos que ainda não haviam feito o exame preventivo ou que estavam sem fazê-lo há mais de três anos. Nesta segunda fase, foram examinadas mais de 3,8 milhões de mulheres. A partir de 2002, não foram efetuadas novas campanhas. O programa passou a dar ênfase ao aperfeiçoamento da rede de atenção oncológica, através das ações de assessoria técnica aos estados, da modernização tecnológica do Siscolo (DATASUS) e da revisão de indicadores para monitoramento de suas ações (BRASIL, 2002). 
Os resultados do Viva Mulher ainda não se expressam de forma positiva na mortalidade por câncer de colo do útero no Brasil. No entanto, é inegável sua contribuição no que concerne ao aumento do número de exames anuais efetuados pelo rede pública de saúde e na formação de uma estrutura nacional para o controle da doença. ${ }^{2}$

\section{Primeiras iniciativas para a formação de citotécnicos no Brasil}

Como vimos, o final dos anos 1960 marcaram uma profunda transformação no processo de controle do câncer cervical no Brasil. O modelo anterior, centrado em consultórios e dispensários e no uso combinado da colposcopia e da citologia, começa a conviver com campanhas ou programas de prevenção baseados no rastreamento a partir do uso em grande escala da citologia exfoliativa. Nesse contexto, a leitura das lâminas de exames citológicos vai se tornando uma atividade central à saúde pública, necessitando de profissionais com formação específica que garantisse a qualidade de seu trabalho.

O primeiro curso para a formação de citotécnicos de que temos notícia no Brasil foi instituído em 1968, no Centro de Pesquisa Luiza Gomes de Lemos, instituição vinculada à Fundação das Pioneiras Sociais. ${ }^{3} \mathrm{O}$ curso tinha a duração de dois anos e funcionava em regime de horário integral. Seu programa se dividia em dois períodos, um básico e um de treinamento especializado (cada um com mil horas aula). No primeiro ano, era oferecida uma formação básica, centrada em citologia da cérvice uterina. $\mathrm{O}$ segundo ano funcionava como uma especialização, onde o aluno também desenvolvia outras aplicações da citologia, como a citologia pulmonar. Nos dois momentos, eram enfatizados os aspectos práticos da leitura das lâminas. Anualmente eram oferecidas 24 vagas, sendo exigida a formação secundária para a participação na seleção.

Durante o II Encontro de Debates sobre Controle do Câncer Ginecológico, realizado em 1973, a Divisão Nacional de Câncer considerou o ensino em citotecnologia oferecido pela Escola de Citopatologia do Centro de Pesquisa Luiza Gomes de Lemos como o padrão de ensino a ser seguido pelos novos centros de formação dos citotécnicos (BARCELOS, 1974). Dessa forma, o modelo de curso baseado num amplo conjunto de conhecimentos no campo das técnicas de citologia passou a ser o padrão para a formação profissional desejada para o citotécnico. 
Em 1973, surgiu outra importante iniciativa no campo da formação de citotécnicos. A Divisão Nacional de Câncer, contando com a assistência técnica da OPAS, financiou a criação de uma escola de citotécnicos no Instituto Brasileiro de Pesquisas em Oncologia e Obstetrícia (IBEPOG), no Estado de São Paulo. O curso era uma decorrência das novas diretrizes da Divisão Nacional de Câncer, que visavam a expandir as campanhas de rastreamento efetuadas na cidade de São Paulo para outras regiōes do estado. Naquele momento, a falta de citotécnicos era o funil que inviabilizava o desenvolvimento dessas campanhas, e a Escola de Formação de Citotécnicos do IBEPOG era uma das iniciativas do DNC para sanar esse problema (CAPUCCI, 2003). Este curso tinha estrutura igual ao das Pioneiras Sociais: duração de dois anos, contando com atividades diárias em tempo integral.

Ainda em 1973, foi reformulado o curso de formação de citotécnicos da Divisão Nacional de Câncer, no Instituto Nacional de Câncer, no Rio de Janeiro. ${ }^{4}$ Sua estrutura se assemelhava às iniciativas já observadas e sua criação se inseriu no esforço da DNC de ampliar a formação de citotécnicos no país (BRASIL, 1973). Outra instituição pioneira na formação de citotécnicos foi a Liga Bahiana Contra o Câncer. Criada em 1936, pelo ginecologista Aristides Maltez, a Liga era mantenedora do Hospital Aristides Maltez, em Salvador, que há vários anos trabalhava na prevenção do câncer ginecológico com o uso da citologia exfoliativa. Contando com auxílio financeiro do PNCC, em novembro de 1973, a Liga inaugurou uma escola de formação de citotécnicos anexa ao Hospital Aristides Maltez. Em seus primeiros dois anos de atividades, a escola formou 41 citotécnicos (MALTEZ, 1975).

Durante a primeira metade da década de 1970, o número de centros formadores de citotécnicos passou por uma grande ampliação. Em 1974, além das instituições já citadas, atuavam na formação desses profissionais o Instituto Nacional de Câncer, no Rio de Janeiro; a Santa Casa de Misericórdia de São Paulo; a Faculdade de Medicina da Universidade Estadual de Campinas; o Centro de Treinamento de Recursos Humanos da Fundação Amaury de Medeiros, da Secretaria de Saúde do Estado de Pernambuco; a Faculdade de Medicina da Universidade Católica de Porto Alegre; o Instituto do Câncer de Londrina; a Secretaria de Saúde do Estado de Minas Gerais e a Secretaria de Saúde do Estado da Bahia (BARCELOS, 1974). 
A expansão do Ensino da Citotecnologia no Brasil se relacionou à necessidade da formação de profissionais para atuar no Programa Nacional de Controle do Câncer (CUNHA, 1978). Para a realização do programa, observou-se a necessidade de qualificação de pessoal médico e não-médico e, para tanto, era necessário intensificar e homogeneizar essa qualificação. No entanto, a expansão desses cursos não solucionaria o problema da formação de pessoal para a leitura de exames. O longo período necessário para uma formação qualificada, as limitações físicas e orçamentárias e de pessoal técnico para a formação de um número maior de profissionais e a busca do mercado privado de saúde por mão de obra de baixíssimo custo fazia com que a leitura de laminas de citologia (particularmente em laboratórios privados) permanecesse sendo efetuada por trabalhadores sem a devida formação.

\section{Os citotécnicos diante da lei}

A gênese do processo de normatização da profissão do citotécnico começou bem antes do período das grandes campanhas de rastreio do câncer de colo do útero e se relaciona à criação da Sociedade Brasileira de Citologia (SBC). Essa instituição foi criada em 1956, e teve atuação destacada na busca do reconhecimento da citopatologia como uma especialidade médica. Apenas no início da década de 1970 ela alcançaria esse objetivo, conseguindo que a Associação Médica Brasileira passasse a exigir concurso público para conferir o título de Médico Especialista em Citopatologia. O primeiro concurso para a obtenção desse título foi realizado em 1971, pela própria SBC (BARCELOS, 1974).

O reconhecimento da citopatologia como especialidade médica foi seguido do reconhecimento dos citotécnicos como profissionais responsáveis pela primeira leitura das lâminas de exames citológicos. Em 1973, a partir das discussóes ocorridas no já mencionado II Encontro de Debates sobre o Controle do Câncer Ginecológico, a Divisão Nacional de Câncer estabeleceu os padrões básicos para a formação dos citotécnicos. As provas para a obtenção do certificado de suficiência em citotecnologia passariam a ser promovidas pela Sociedade Brasileira de Citologia, sob a coordenação da Divisão Nacional de Câncer. Para a realização das provas, o profissional de nível médio precisava ter sido treinado em uma escola de formação de citotécnicos. Ainda em 1973, foi realizado o primeiro concurso para a concessão de um certificado de suficiência em citotecnologia (BARCELOS, 1974) 
A criação do certificado foi o primeiro passo na normatização dessa nova categoria profissional que aos poucos se delineava. Também se caracterizou como a primeira iniciativa para a definição das qualificações necessárias para o cumprimento de suas funções. A expansão das campanhas de rastreio do câncer de colo do útero, no início da década de 1970, modificou esse contexto e ampliou as preocupações com a formação dos citotécnicos. Além disso, no mesmo período, observa-se a expansão da medicina diagnóstica, principalmente dos laboratórios privados, onde profissionais sem a devida formação desempenhavam a função. Essa nova realidade também fez com que se tornasse imprescindível a melhor definição das atribuições atinentes a esse profissional.

Diante desse quadro, a Divisão Nacional de Câncer resolveu participar ativamente no processo de expansão da formação de citotécnicos. Em 1976, uma auditoria técnico-científica avaliou os cursos existentes e identificou deficiências na padronização dos programas de formação e no escopo de atividades relacionadas aos citotécnicos. As resoluções decorrentes apontaram para a necessidade de criação da habilitação de citotécnico, bem como o estabelecimento de currículo mínimo para sua formação. A auditoria também levou à oficialização, no âmbito do Ministério da Saúde, de quatro Centros de Treinamento em Citotecnologia: Centro de Citodiagnóstico (FUSAM/PE), Laboratório de Anatomia Patológica da Secretaria de Saúde do Rio Grande do Sul, Instituto Nacional de Câncer e Instituto Brasileiro de Controle do Câncer/SP (CUNHA, 1978).

Para operacionalizar essas postulações, foi constituído um grupo de trabalho que apontou os seguintes requisitos necessários para o citotécnico exercer sua profissão: a) comprovação de conclusão do curso de Formação de Técnico em Citologia (citotécnico), obtida em cursos mantidos pela Divisão Nacional de Câncer (Centro de Formação de Citotécnicos), Ministério da Saúde ou outras Instituições cadastradas na Divisão Nacional de Câncer (DNC); b) certificado de aprovação na "Prova de Suficiência em Citotecnologia", promovida pela Sociedade Brasileira de Citologia; c) reavaliação dos conhecimentos em citotecnia a cada três anos (CUNHA, 1977).

O grupo de trabalho também formulou uma proposta curricular para a criação de cursos profissionalizantes em citotecnologia em nível de segundo grau, para ser discutida com o Ministério da Educação e Cultura. Nesse período, o ensino profissional era visto como um instrumento fundamental para a manutenção da 
expansão econômica, sendo que, em 1971, uma nova Lei de Diretrizes de Base da Educação havia estabelecido a obrigatoriedade da habilitação profissional no ensino secundário. Dentro desse contexto, a Divisão Nacional de Câncer procurou ampliar a oferta de formação de citotécnicos, transformando-a em uma das habilitações do ensino profissionalizante (CUNHA, 1978). A despeito de o objeto dessa proposta ter ficado mais de dez anos para ser regulamentada, sua criação, no âmbito do Ministério da Saúde, mostra o interesse da saúde pública na ampliação da formação dos citotécnicos nesse período.

Em meados da década de 1980, a DNC voltou a mover esforços para padronização e ampliação da oferta de cursos de formação de citotécnicos. Em setembro de 1985, a OPAS organizou em Washington a reunião de um grupo de especialistas, com o objetivo de determinar o perfil ocupacional e educacional do pessoal de nível médio na área de citologia e formular recomendações sobre a formação deste pessoal na América Latina e no Caribe. Em 1986, realizou-se um Seminário de Integração do Setor Saúde para o Controle do Câncer CérvicoUterino, e o grupo de trabalho recomendou apoio aos cursos em funcionamento no país, bem como a criação de outros polos de formação de pessoal na área de citologia. Em reunião realizada em Brasília, no ano seguinte, mais uma vez um grupo de trabalho apresentou novo estudo para homogeneização dos cursos de citotécnico mantidos pelo Ministério da Saúde.

Em 1988, o Ministério da Saúde mais uma vez tentou levar à frente a proposta de incluir a formação de citotécnicos no âmbito do ensino profissionalizante. Um acordo interministerial firmado entre Ministério da Saúde, Ministério da Educação e Cultura, Ministério da Previdência e Assistência Social, Ministério da Ciência e da Tecnologia e OPAS constituiu mais um grupo de trabalho relacionado aos citotécnicos. Tratava-se de elaborar uma proposta de habilitação e criação de um currículo mínimo, a ser aprovada pelo Conselho Federal de Educação. Em abril de 1989, o Parecer no 353/89 do Conselho Federal de Educação (CFE), publicado na Documenta no 340, editada pelo Ministério da Educação e Cultura, deferiu a proposta, definindo os mínimos curriculares para a formação do profissional do técnico em citologia no ensino profissionalizante de segundo grau e prescrevendo as atribuiçōes destes profissionais (BRASIL, 1989).

A habilitação profissional do citotécnico era de extrema importância para o controle da qualidade dos exames citológicos. Da mesma forma, a ampliação 
da oferta de mão de obra qualificada era fundamental para a manutenção das estratégias de prevenção. No entanto, ao longo de duas décadas, a relevância atribuída à função desempenhada pelos citotécnicos não permitiu reconhecer sua contribuição para o controle do câncer do colo do útero no país. Mesmo o Parecer no 353/89, do CFE, não teve a capacidade de promover a formalização pleiteada pelos formuladores de políticas e gestores de saúde, permanecendo até hoje como letra morta.

Os aspectos acima descritos sobre os citotécnicos exemplificam muitos dos problemas enfrentados por outros trabalhadores técnicos em saúde no Brasil. O treinamento em serviço, a falta de padronização dos cursos (muitas vezes, cursos rápidos em instituiçôes privadas, que seguem somente critérios do mercado) e a busca pela regulamentação marcam as condições de formação e de trabalho do técnico em saúde ainda hoje e sinalizam os grandes obstáculos que devem ser enfrentados para a melhoria das políticas de educação profissional em saúde no país (PRONKO, 2001; GIRARDI; SEIXAS, 2002).

\section{Conclusão}

Os autores que se dedicaram à análise da organização das profissões em saúde observam que uma profissão se constitui a partir dos embates pela conquista e preservação dos mercados de serviços e pela obtenção de autonomia, legitimidade, e poder de autorregulamentação para o exercício de atividades específicas. Sob esse ponto de vista, o conceito de profissão inclui três diferentes aspectos: o domínio de um conhecimento específico, o monopólio do mercado de trabalho e a formalização ou padronização da conduta profissional, através de mecanismos de regulação internos e externos (FREIDSON, 2009).

No caso dos citotécnicos, a maior parte desses aspectos esteve ausente no período observado, impossibilitando sua organização como grupo profissional específico. No que tange ao seu mercado de trabalho, afirmamos o desenvolvimento da demanda pela atividade que desempenhavam, a partir da expansão das campanhas de prevenção iniciadas na década de 1970. No entanto, esse momento também é marcado pelo grande desenvolvimento da medicina privada, em especial da medicina diagnóstica baseada em planos de saúde. Nesse contexto, os laboratórios privados passaram a executar um grande número de exames citológicos para a saúde complementar, além de vender serviços para a 
saúde pública. Nesses laboratórios, era comum a utilização de técnicos sem a devida qualificação, aptos a aceitar salários baixíssimos, o que se caracterizou como um entrave à homogeneização da formação e habilitação dos citotécnicos. Embora o Estado tenha atuado nesse sentido, através de iniciativas para a expansão e homogeneização dos cursos de formação, a existência de formas tão díspares de profissionais dificultava esse processo.

Em relação à padronização da formação dos citotécnicos, as iniciativas estatais mostram a existência de várias proposiçôes, configurando diferentes formas de ver a mesma atividade. De um lado, observamos os técnicos das escolas pioneiras (principalmente a do Rio de Janeiro) postulando a padronização da formação a partir de seu modelo de curso - de longa duração e formação ampliada. Apostando em outras estratégias, os defensores da criação de cursos de citotecnologia no ensino profissionalizante buscavam ampliar a oferta de formação, sem se fixar na amplitude curricular das escolas já existentes. Essas diferentes visões sobre a formação espelham diferentes formas de pensar a extensão do trabalho do citotécnico.

No que tange à autonomia do trabalho realizado, observamos que os citotécnicos sempre enfrentaram dificuldades concernentes à relação de seu trabalho com as profissóes de nível superior a eles vinculadas. $\mathrm{Na}$ luta pelo monopólio de frações do mercado da saúde por diferentes profissões, a responsabilidade pela supervisão do trabalho do citotécnico foi vista de diferentes maneiras, sempre tendo como base a atuação de sociedades profissionais. De início, relacionada aos citologistas, a atividade passou a ser defendida como atinente ao âmbito de diversas profissões da área da saúde. A partir da década de 1990, biólogos, farmacêuticos e biomédicos ingressaram no campo da citologia e passaram a se mobilizar na defesa da possibilidade de atuarem na supervisão de atividades laboratoriais, em particular na supervisão da leitura de lâminas citológicas, o que de pronto gerou a reação dos médicos. Opondo-se à atuação de profissionais de diversas formações biomédicas na supervisão dos citotécnicos, o Conselho Federal de Medicina, entre as décadas de 1980 e 1990, emitiu vários pareceres $(36 / 89,37 / 89,1473 / 97)$ reafirmando a citologia e a patologia como especialidades médicas e acrescentando que qualquer resolução contrária seria uma invasão ao seu mercado de trabalho - no entanto, essa questão continuou controversa. Assim, para a conformação da citotecnia como área profissional, a indefinição das relações com outros campos profissionais também se mostrou 
um problema, na medida em que dificultou seu processo de institucionalização como profissão autônoma.

A todos esses fatores se soma a questão da identidade dos citotécnicos como grupo profissional. Nesse ponto vale ressaltar que, por todo o período estudado, esses profissionais não se afirmaram como um grupo com identidade específica, aptos a construir os mecanismos de autorregulação de sua atuação. Até recentemente, sua identidade se definiu a partir do Estado e das sociedades científicas, que buscaram de diversas formas normatizar sua formação e suas atividades.

Embora transcenda o escopo deste trabalho, é importante mencionar que, nos últimos anos, a institucionalização do programa de prevenção do câncer do colo do útero e a necessidade de garantia de qualidade dos exames executados fizeram com que a questão da formação do citotécnico voltasse ao centro das atençôes. Nesse novo contexto, a busca pela normatização da profissão tem como protagonista o Instituto Nacional de Câncer.

Como órgão responsável pelas políticas de controle do câncer, o Instituto passou a se empenhar na busca de soluções para a melhoria da formação e atuação dos citotécnicos. A partir de 2008, a Coordenação de Educação do Instituto Nacional de Câncer (CEDC/INCA) e a Coordenação Geral das Ações Técnicas de Educação em Saúde (Departamento de Gestão da Educação em Saúde/SGTES/MS) articularam-se para formular políticas relativas à formação, ao desenvolvimento profissional e à educação permanente dos trabalhadores da saúde nos níveis (superior e técnico) do SUS. Nesse processo, mais uma vez a formação do citotécnico passou a ser alvo da ação positiva do Estado, agora considerada como uma das quatro áreas prioritárias do Programa de Formação de Profissionais de Nível Médio para a Saúde (PROFAPS).

A novidade desse processo é que a indução estatal para a normatização da profissão trouxe para o centro da discussão os próprios profissionais. Em agosto de 2009, o INCA promoveu a I Jornada Internacional de Citotecnologia, que reuniu cerca de 200 citotécnicos, provenientes de 17 estados da federação. Nesse evento, criou-se a Associação Nacional de Citotécnicos (Anacito), com o objetivo geral de trabalhar pelos interesses da categoria. Em paralelo, o INCA iniciou um processo de negociação para a assinatura de convênio com uma instituição de ensino técnico - a Escola Politécnica de Saúde Joaquim Venâncio (EPSJV/FIOCRUZ) -, para proceder à certificação dos profissionais e ao credenciamento do seu curso. 
Seguindo as premissas dos que, na década de 1970, se empenharam na busca de normatização da habilitação dos citotécnicos, os profissionais hoje envolvidos nesse processo afirmam que a aprovação da habilitação profissional do técnico em citologia possibilitará a uniformidade dos currículos, a avaliação da qualidade e maior eficiência dos investimentos nos cursos de formação, o que resultaria no fortalecimento do Programa Nacional de Controle do Câncer do Colo do Útero. ${ }^{6}$

\section{Referências}

ABREU, E. Editorial: "Pro-Onco 10 anos". Revista brasileira de Cancerologia, v.43, n.4, p.237-238, 1997.

AQUINO, E.M.L. et al. Situação atual da detecção precoce do câncer cérvico-uterino no Brasil. Cad. Saúde Pública, Rio de Janeiro, v.2, n.1, p.53-65, mar 1986.

BARCELOS, J.M. Introdução. In: CAMPOS DA PAZ, A.; BARCELOS, J.M. Concursos de especialização em citopatologia. Rio de Janeiro: Escola de Citopatologia / Centro de Pesquisas Luiza Gomes de Lemos / Fundação Pioneiras Sociais, 1974.

BRASIL. Ministério da Saúde. Secretaria de Assistência à Saúde. Instituto Nacional do Câncer. Viva Mulher: câncer do colo do útero, informações técnico-gerenciais e ações desenvolvidas. Rio de Janeiro: INCA, 2002.

Ministério da Saúde. Secretaria de Assistência à Saúde. Instituto Nacional do Câncer. Viva Mulher: Relatório Novembro de 2000, metas cumpridas e novas perspectivas. Rio de Janeiro: INCA, 2000.

. Ministério da Educação e Cultura. Conselho Federal de Educação. Parecer 353/89. Criação das habilitaçôes profissionais de técnico em registros de saúde, técnico em equipamentos médico hospitalares e técnico em citologia. Brasília/DF, Documenta n. 340 , abr 1989.

Ministério da Saúde. Secretaria de Assistência Médica. Divisão Nacional de Câncer. Instituto Nacional de Câncer. I Curso para a Formação de citotécnicos: Programa 1973. Rio de Janeiro: INCA, 1973.

CAPUCCI, F. Filosofia Sampaio Góes: Instituto Brasileiro de Controle do Câncer - IBCC 35 anos. São Paulo: Activa Comunicação, 2003.

CARMO, P.A.O. et al. A História da Mastologia no INCA. Revista brasileira de Cancerologia, v.48, n.1, p.135-138, 2002.

CUNHA, M.P. Ensino da Citotecnologia. Revista brasileira de Cancerologia. Brasília, v.28, n.4, p.41-46, jul-ago 1978. 
. Módulo mínimo para um laboratório de citologia: organização e administração.

Revista brasileira de Cancerologia. Brasília, v.27, n.5, p.37-48, set-out 1977.

FREIDSON, E. Profissão Médica. Um estudo de sociologia do conhecimento aplicado. São Paulo: Unesp, 2009.

GIRARDI, S.N.; SEIXAS, P.H. Dilemas da regulamentação profissional na área de saúde: questões para um governo democrático e inclusionista. In: MINISTÉRIO DA SAÚDE. Projeto de profissionalização dos trabalhadores da área de enfermagem. Brasília, v.2, n.5, 2002. HAKAMAL, M. et al. Evaluation of screening programmes for gynaecological cancer. $\mathrm{Br}$. J. Cancer, n.52, p.669-673, 1985.

HORWITZ, A. Prologo. In: ORGANIZACIÓN PANAMERICANA DE LA SALUD. Oficina Sanitaria Panamericana. Manual de normas y procedimentos para el control del câncer del cuello uterino. Washington, DC: OPAS, 1972 (Publicación Cientifica n. 248).

INSTITUTO NACIONAL DO CÂNCER. Estimativa de Câncer no Brasil, 2012: incidência de câncer no Brasil. Rio de Janeiro: INCA, 2011.

LAGO, T.G. Politicas nacionais de rastreamento do câncer de colo uterino no Brasil: análise do período 1998-2002. Tese (Doutorado em Saúde Pública) - Universidade Estadual de Campinas, Campinas, 2004.

LOWY, I. Preventive strikes: women, precancer, and prophylactic surgery. Baltmore: Johns Hopkins University Press, 2010.

MALTEZ, C.A. Relatório da Liga Bahiana contra o Câncer: atividades - realizações. Arquivos de Oncologia, v.16, n.1, p.95-97, 1975.

PINOTTI, J.A.; ZEFERINO, L.C. Programa de controle de câncer cérvico uterino. Campinas: EdUnicamp, 1987 (Série Saúde da Mulher).

PRONKO, M. A formação dos trabalhadores técnicos em saúde no Brasil e no Mercosul. Rio de Janeiro: EPSJV, 2011.

TEIXEIRA, L.A.; Lowy, I. Imperfect tools for a difficult job: Colposcopy, colpocytology and screening for cervical cancer in Brazil. Social Studies of Science, v.41, n.4,p. 585-608, Aug 2011. WORLD HEALTH ORGANIZATION. Early Detection. Cancer control: knowledge into action. WHO guide for effective programmes; module 3. Geneva: WHO Press, 2007. Disponível em: <http://www.who.int/cancer/modules/en/> Acesso em: set 2011.

\section{Notas}

${ }^{1}$ Menções a essas controvérsias encontram-se nas entrevistas realizadas no âmbito do Projeto História do Câncer - atores, cenários e políticas públicas, uma parceria entre a Casa de Oswaldo Cruz/Fiocruz e o INCA. Ver em especial a entrevista de Luiz Claudio Thuler, realizada em 2010. 
${ }^{2}$ Entre 1995 e 2003, o crescimento no número anual de exames apresentados ao SUS foi bastante de $81 \%$ (LAGO, 2004).

${ }^{3}$ O Centro de Pesquisa Luiza Gomes de Lemos foi criado pelo presidente Juscelino Kubitschek, após a morte de sua sogra, Luiza Gomes de Lemos, em decorrência de um câncer uterino. Seu primeiro diretor foi o médico Arthur Fernandes Campos da Paz, que havia sido responsável pelo tratamento da sogra do presidente (CARMO, et al., 2002).

${ }^{4} \mathrm{O}$ curso era uma atividade conjunta do INCA e do IBEPOG e contava com a colaboração financeira da OPAS. Dirigido por Onofre Ferreira de Castro, do INCA, e por Jesus Carlos Machado, do IBEPOG, o curso contava ainda com o médico Rodrigo Prado, da OPAS, como professor convidado (BRASIL, 1973). Para a realização dessa iniciativa, Onofre de Castro contava com sua experiência, desde 1969, na formação de citotécnicos nas dependências do Laboratório Central de Citopatologia (LCCP) da Maternidade-Escola da Universidade Federal do Rio de Janeiro. Menções sobre o curso de formação de citotécnicos dessa instituição podem ser encontradas nos documentos pessoais de Onofre de Castro, reunidos no Arquivo da Academia Nacional de Medicina (Código de referência: BR ANM MT 558).

${ }^{5}$ Em 1956, o ginecologista Arnaldo de Moraes, que dirigia o Instituto de Ginecologia da Faculdade de Medicina do Rio de Janeiro, e a médica Clarice do Amaral Ferreira, que vinha elaborando trabalhos sobre citologia nesse instituto, fundaram a Sociedade Brasileira de Citologia.

${ }^{6}$ Os três autores participaram igualmente na pesquisa de fontes, discussōes dos dados e elaboração do artigo. 


\section{Abstract}

\section{The expansion of screening for cervix cancer and}

the training of cytotechnologists in Brazil

The paper discusses the emergence of the professional category of cytotechnologists in Brazil and its history from the 1970s and late 1990s. At the beginning of this period, the Pan American Health Organization considered cervix cancer as a serious public health problem, which can be controlled in developing countries. In this context, arose the first campaigns tracking the disease in the country. The institutionalization of these campaigns made the cytotechnologists indispensable for the disease control. With the expansion of demand for its activity and the emergence of the first initiatives for its formation, new issues begin to emerge. How these new professionals could be trained in adequate quantity and quality? What is the appropriate curriculum to their duties and responsibilities? How to monitor the functioning of the courses? In the field of standardization of the new activity, other questions arise: how to secure a monopoly on the activity performed, how to characterize their specificity, which required training to those who will exercise it? These points become topics of debates and negotiations, a typical process of consolidating a new profession. The process of institutionalization of the program of prevention of cancer of the cervix and the consequent need for quality assurance tests performed have made these issues return to the limelight. This study aims to contribute to the expansion of knowledge about the formation of cytotechnologists, and the more general context, the process of health training in Brazil.

> Key words: cervix cancer; Pap smear; screening programs; health technologists. 